\title{
La comunidad local en la valoración del patrimonio rural
}

\section{La escuela Francisco Arias en Lavalle}

\author{
The local community in the appreciation of rural heritage. \\ Francisco Arias school in Lavalle
}

\section{Isabel Durá-Gúrpide}

Universidad Nacional de Cuyo, Mendoza (Argentina)

\section{Matías J. Esteves}

Centro de Investigaciones Científicas y Técnicas, Mendoza (Argentina)

Instituto de Ciencias Humanas, Sociales y Ambientales

\section{Isabel Durá-Gúrpide}

Arquitecta, Universidad de Navarra (España). Especialista en restauración y rehabilitación de arquitectura,

Universidad de Navarra (España).

Estancia de investigación en la ETH de Zúrich (Suiza).

Docente, Universidad de Navarra (España).

Docente, Universidad de Congreso, Mendoza (Argentina).

Becaria posdoctoral, CONICET, en INCIHUSA, Mendoza (Argentina).

Docente, Universidad Nacional de Cuyo, Mendoza (Argentina).

(i) http://orcid.org/0000-0003-|475-3372

(10idurag@gmail.com

Matías J. Esteves

Arquitecto, Universidad de Mendoza (Argentina).

Máster en arquitectura y urbanismo sostenible, Universidad Internacional de Andalucía (España).

Doctor en arquitectura y urbanismo, Universidad Nacional de San Juan (Argentina).

Docente, Universidad de Mendoza (Argentina).

Becario posdoctoral, CONICET.

(iD) http://orcid.org/0000-0002-7688-8363

@ mesteves@mendoza-conicet.gob.ar

Durá-Gúrpide, I. y Esteves M. J. (2020). La comunidad local en la valoración del patrimonio rural. La escuela Francisco Arias en Lavalle. Revista de Arquitectura (Bogotá), 22(2), 12-23. https://doi.org/10.14718/RevArq.2020.2281

\section{(c) (1) (8)}

\section{Resumen}

El presente trabajo aborda el estudio de la escuela Francisco Arias de Lavalle (Mendoza, Argentina) desde la perspectiva del patrimonio cultural. Las escuelas rurales mendocinas se presentan como un tema de especial interés, tanto por la dimensión patrimonial de estas construcciones como por la relevancia de su impacto en su contexto de inserción. Se detecta una carencia respecto al estudio y la valoración del patrimonio edilicio en zonas rurales de Mendoza, lo que acentúa su actual vulnerabilidad. Es así como se indaga, a partir de un caso de estudio, en la dimensión patrimonial de un edificio de uso cotidiano como la escuela y su potencial como recurso para el desarrollo local y como elemento de cohesión en territorios rurales. Para ello, se recurrió al análisis de documentos, a la observación directa y a entrevistas semi-estructuradas. Los resultados obtenidos señalan la relevancia del patrimonio edificado para una comunidad, no solo por sus valores materiales, sino también como depositario de aspectos simbólicos y la importancia de considerar a la población local en el estudio, la valoración y la conservación del patrimonio.

Palabras clave: Escuela primaria; identidad cultural; memoria colectiva; patrimonio cultural; desarrollo rural; educación rural; educación complementaria;

\section{Abstract}

The perspective of Cultural Heritage in relation to the study of Francisco Arias school in Lavalle (Mendoza, Argentina). Rural schools in Mendoza are presented as a topic of special interest, as much for the patrimonial heritage dimension of these constructions as for the relevance of their impact in its insertion site. Besides, the need of such a study is based upon a deficiency detected regarding the study and valuation of the build heritage in rural areas of Mendoza, therefore accentuating its current vulnerability. Thus, this work explores from a case study, the heritage dimension of a building daily inhabited like a school and its potential, both as a resource for local development and as an element of cohesion in rural territories. To do this, methods such as document analysis, direct observation and semi-structured interviews were used. The results hint at the relevance of the built heritage for a community, not only for its material values but also as a repository of symbolic aspects, besides the importance of considering the local population throughout the processes of study, valuation and conservation of their cultural heritage.

Key words: Elementary school; cultural identity; collective memory; cultural heritage; rural development; rural education; supplementary education; 


\section{Introducción}

El presente estudio se enmarca dentro de la línea de investigación que se desarrolla en el equipo de Historia y Conservación Patrimonial, del Instituto de Ciencias Humanas, Sociales y Ambientales (INCIHUSA) del Centro Científico Tecnológico de la provincia de Mendoza, Argentina. El trabajo realizado presenta continuidad con los proyectos de investigación efectuados por el grupo — dedicado a la identificación, la puesta en valor y la activación del patrimonio cultural de Mendoza - y se vincula a las investigaciones posdoctorales de los autores, financiadas por el Consejo Nacional de Investigaciones Científicas y Técnicas (CONICET). Se propone avanzar en el estudio del patrimonio cultural de Mendoza y extender su valoración fuera del Área Metropolitana, principal foco de estudio hasta el momento.

Gutiérrez y Petrina (2011) se han referido a la necesidad de abordar el patrimonio edilicio desde una categoría más amplia, la de patrimonio cultural, y no solo desde el reconocimiento histórico. Así mismo, señalan la pertinencia de contemplar la dimensión ambiental del patrimonio en el contexto latinoamericano, en relación con la necesidad de aprovechar las construcciones con posibilidad de vida útil. En las últimas décadas, el patrimonio cultural se ha revelado como un campo de conocimiento amplio y pluridisciplinar, que no solo se vincula con aspectos materiales, sino que también involucra a los aspectos simbólicos de una determinada población en una relación articulada.

Cabe referirse también a la condición particular de las escuelas rurales como patrimonio local, categoría que lleva asociadas características específicas para considerar. Según Prats, el factor escala introduce variaciones significativas en la conceptualización y la gestión del patrimonio local. Dicho patrimonio "está compuesto por todos aquellos objetos, lugares y manifestaciones locales que, en cada caso, guardan una relación metonímica con la externalidad cultural" (2005, p. 23). Según ello, el interés del patrimonio local no radica en la creación de un flujo de visitantes considerable, sino en el importante significado que tiene para su comunidad como foro de la memoria, y cuya activación permite, partiendo de preocupaciones y retos del presente, reflexionar sobre el pasado para proyectar el futuro. Estas consideraciones se alinean con las de United Nations Educational, Scientific and Cultural Organization (UNESCO, 2016), que entiende el patrimonio cultural como un recurso estratégico para la creación de ciudades más inclusivas, creativas y sostenibles. Además, en el caso particular del medio rural, se señala el potencial de los recursos culturales, materiales e inmateriales, para mejorar el contexto regional general y propiciar un desarrollo territorial equilibrado.

El tema específico que se trata, la escuela rural, resulta de especial interés tanto por el valor social y arquitectónico de estas construcciones como por la relevancia de su impacto en el contexto de inserción. Ciertamente, estos edificios se vinculan a su entorno y constituyen elementos de referencia y cohesión de una comunidad. En la provincia de Mendoza, el origen de muchas de las escuelas rurales se remonta a finales del siglo XIX — coincidiendo con la extensión de la educación pública y con importantes movimientos migratorios-, cuando emprendieron su actividad en construcciones prestadas o arrendadas pensadas para otros usos; sus edificios específicos se construyeron con posterioridad, a partir de una demanda social. Las distintas iniciativas estatales de construcción de escuelas rurales en Mendoza tuvieron como objetivo común la modernización del ámbito rural: el edificio escolar se convertiría en un símbolo de progreso. Así, sus diseños atendieron en cada caso a las ideas de vanguardia contemporáneas, relativas a la disciplina de la arquitectura y de la pedagogía, y además, a las condiciones locales y del territorio.

La obra pública mendocina en la década de 1930 ha sido reconocida gracias a sus valores históricos y arquitectónicos por distintos estudios especializados (Raffa, 2009; Raffa y Cirvini, 2013; Cremaschi, 2015); no obstante, solo algunos de estos edificios han obtenido el reconocimiento de su dimensión patrimonial: recientemente han sido declarados como monumentos históricos nacionales el Museo Cornelio Moyano —-balneario Playas Serranas en su origen-y las escuelas Videla Correas y Urquiza, ubicadas dentro de la trama urbana en las ciudades de Mendoza y de Maipú, respectivamente (Ministerio de Justicia y Derechos Humanos, 8 de agosto de 2017). Otras de las escuelas construidas durante el periodo por los mismos arquitectos y con los mismos criterios no han sido aún valoradas oficialmente; entre ellas, la obra objeto de estudio. Interesa señalar que la mayor parte de las obras reconocidas de la provincia como patrimonio se circunscriben al área metropolitana de Mendoza, y son tareas pendientes la identificación y la puesta en valor del patrimonio arquitectónico del ámbito rural.

La ausencia de estudios vinculados al patrimonio arquitectónico educativo de las zonas rurales de Mendoza incita la exploración del tema. El trabajo que se presenta forma parte de una investigación de mayor escala que atiende a las escuelas rurales construidas en la provincia durante la primera mitad de siglo XX'1 . En esta ocasión, se hace el estudio del caso concreto de la escuela Francisco Arias, elección motivada por el anuncio de su próxima demolición (Gobierno de Mendoza, 2017). A partir de las entrevistas realizadas a distintos actores locales - pobladores, maestros y directivos de la escuela - se observa, en un contexto de desprotección patrimonial por parte de las instituciones provinciales, la importante incidencia que tiene la comunidad para alcanzar la conservación de un bien ligado a su significado asociado y a la variación de este a lo largo del tiempo.

1 Línea principal de trabajo de la autora Isabel Durá Gúrpide. 
La escuela Francisco Arias, objeto de estudio, en el distrito de La Pega, pertenece al departamento de Lavalle, en la provincia de Mendoza. Si bien esta escuela inició su actividad en 1919, lo hizo en un principio dentro de una construcción prestada: una vivienda de adobe. Fue en 1934 cuando el gobierno provincial construyó un edificio ex profeso, como parte de un importante plan de infraestructura pública que contempló la construcción de escuelas (Raffa, 2008; Cattaneo, 2011), y que atendió tanto a las zonas urbanas como al ámbito rural. El edificio de la escuela Arias se ha conservado hasta la actualidad y mantiene su uso original, aunque acumula desde entonces distintas reformas y ampliaciones que han acompañado a los cambios demográficos del lugar y a los requerimientos educativos.

Con frecuencia, el uso sostenido y cotidiano de la edificación escolar hace pasar su valor inadvertido. Además, en este caso se suma su ubicación periférica respecto a centros urbanos y el desconocimiento de sus valores materiales y simbólicos por parte de la esfera política. Ciertamente, la falta de reconocimiento de la dimensión patrimonial de estas obras ha traído aparejadas deficiencias en su mantenimiento e intervenciones inadecuadas. Esta condición de vulnerabilidad resulta frecuente en el patrimonio construido del siglo $\mathrm{XX}$, $y$ por ello distintas organizaciones internacionales - como UNESCO, ICOMOS y Docomomo- han advertido de la necesidad de actuar con premura para garantizar su conservación.

Se parte de la hipótesis de que el edificio escolar es un bien patrimonial de relevancia que involucra factores materiales y simbólicos de forma articulada y con fuerte incidencia en la cultura local, pues reúne a amplias capas generacionales y se trata de un punto de encuentro de la comunidad. El reconocimiento de los valores de la escuela rural contribuirá a reforzar su significado tanto para las instituciones estatales, responsables de su conservación y activación, como para la población local, que verá potenciada su vinculación con el bien y la identidad locales. El objetivo del trabajo es indagar en el carácter patrimonial de la escuela objeto de estudio identificando sus valores asociados - históricos y artísticos-, así como su significado para la comunidad, con miras a reconocer los principales aspectos que han incidido en su conservación hasta la actualidad y aquellos factores que han determinado su anunciada demolición.

\section{El patrimonio cultural como punto de encuentro entre la arquitectura y el territorio}

Prats (2005) define como criterios de legitimación de un bien patrimonial los siguientes: la naturaleza, la historia y la inspiración creativa. En el caso que nos compete, la eficacia simbólica de un bien se ve reforzada por la condensación de atributos y significados, debido a la combinación de valores de distinto tipo. Silvia Cirvini (2012) ha definido estos valores de manera específica para el patrimonio arquitectónico, donde el valor histórico se refiere a su carácter documental como testimonio cultural del pasado: por su capacidad para brindar información sobre la práctica de la arquitectura y, además, sobre la sociedad que la produjo y la habitó. Por otro lado, los valores creativos se vinculan a la especificidad de la disciplina arquitectónica y atienden a parámetros artísticos, constructivos y espaciales, pero que suceden dentro de determinada dinámica territorial. A lo anterior se suma el carácter simbólico que la población le asigna al edificio, ya que en zonas rurales las escuelas exceden las actividades meramente académicas e incorporan actividades familiares y comunitarias que las refuerzan como referente y punto de encuentro de la comunidad.

Estudios recientes sobre patrimonio advierten sobre la complejidad de la noción de patrimonio cultural cuyo abordaje debe trascender los estudios académicos de las distintas disciplinas implicadas —como la antropología, la arquitectura y la historia del arte, entre otras-, y en el que su significado para la sociedad cobra importancia como criterio de legitimación que, a su vez, se halla estrechamente vinculado a los procesos de patrimonialización (Criado-Boado y Barreiro, 2013). En este sentido, autores como Valera-Pertegás (1996) y Benedetti (2011) consideran que hay determinados espacios o entornos que tienen la capacidad de cargarse de significados y valoraciones, pues son resultado de diversas prácticas sociales realizadas en el tiempo, hasta el punto de que identifican a un grupo social con ellos. Así, interesa poner el foco en la comunidad, en la memoria social y en los valores simbólicos asociados, ya que, según Prats (2005, p. 28), el principal camino para convertir al patrimonio local en un instrumento abierto y de futuro pasa, básicamente, por dar prioridad absoluta al capital humano: las personas antes que las piedras.

Por otro lado, el concepto actual de patrimonio cultural contempla la valoración de un bien no como un objeto aislado, sino en relación con su contexto natural y cultural, como un hecho ensamblado al territorio (Lourés-Seoane, 2001; Llull-Peñalba, 2005; Casado-Galván, 2009). Esto implica considerar las características naturales del territorio en interacción con la cultura de la población que lo habita (Utrera-Santander, 2016; Gómez-Alzate, 2010). Así pues, se propone un abordaje multiescalar, en el cual la arquitectura resulta un intérprete de lo acontecido que refleja la cultura de cada época y la transformación del territorio en el tiempo (Flores, 2004). Esta visión permite considerar el patrimonio más allá de su monumentalidad, aspecto que rigió en un primer momento histórico en el abordaje y el reconocimiento del patrimonio (de Mahieu et al., 2003). 
En el estudio de la relación del patrimonio con el territorio, se encuentran autores que buscan diferenciar el patrimonio urbano del ubicado en zonas rurales. Mediante esta clasificación se pretende identificar diferentes aspectos sociales, económicos y ambientales que influyen en cada uno. El patrimonio arquitectónico rural se analiza a partir de su íntima relación con el territorio donde se encuentra, ya que la relación objeto-contexto proporciona coherencia a estos últimos para su comprensión y su valoración correctas (De la Puente Fernández, 2010; Quintana, 2008). Incluso, muchos autores analizan al patrimonio rural desde el concepto de paisaje cultural para señalar la fuerte relación del territorio, como construcción social, con el objeto arquitectónico (Consejo de Europa, 2000; Nogué, 2007).

Son vastos los trabajos en los que se indaga el patrimonio cultural de zonas rurales en relación directa con el turismo como eje de desarrollo, y en los cuales se analizan tanto los aspectos negativos como los positivos que esta actividad podría generar en una zona determinada. En efecto, diversos autores abogan por el turismo como uno de los principales factores que inciden en la protección y la conservación de los bienes culturales, pero que, a la postre, terminan desvinculando a la población local de su propio patrimonio (Conti y Cravero-Igarza, 2010; Pastor, 2007), a la vez que inciden en la planificación de determinados sectores del territorio en detrimento de otros; es decir, se busca valorar los edificios patrimoniales en torno a zonas definidas como turísticas y en relación con las rutas culturales, pero se descuidan otras zonas del territorio que no presentan una oferta turística, o bien, que poseen referentes patrimoniales de escaso interés más allá de la comunidad. A lo anterior se suma la baja consideración del papel de la población local como actor clave en la gestión y la conservación, y como primera receptora del patrimonio (Luquez-Sánchez, 2014; Venturini, 2010).

\section{Metodología}

Debido a la naturaleza de los objetivos propuestos, se combinaron métodos de investigación asociados tanto a la metodología cuantitativa como a la cualitativa: estudio histórico-narrativo (reconstrucción del contexto histórico), análisis de datos cuantitativos (censos y otros datos), análisis de material visual (planos y fotografías), entrevistas semiestructuradas (distintos actores vinculados) y análisis del discurso (aspectos simbólicos).

En una primera fase se acometieron la recolección de datos, la contextualización y la caracterización de los valores arquitectónicos de la obra original. Después se identificaron las transformaciones del edificio de la escuela a lo largo del tiempo — vinculadas a cambios históricos, políticos y sociales de su entorno y su comunidad- hasta definir su situación actual en relación con su estado de conservación y su valoración por parte de los distintos actores relacionados: tanto por su comunidad como por las instituciones de las que depende. Esto permitió, por un lado, definir el valor patrimonial del edificio de la Escuela Arias y, además, evaluar la incidencia de los distintos actores relacionados en su valoración y su conservación.

En el desarrollo de la investigación, se consultaron y se analizaron distintas fuentes documentales, con miras a obtener datos respecto al proyecto original del edificio y sus sucesivas transformaciones, la historia de la escuela y su vinculación con el territorio. Se acudió a fuentes como: prensa local, memorias de gobierno, memorias de la escuela, planos y fotografías (de gobierno, del archivo escolar y facilitadas por vecinos). De esta manera se obtuvieron datos que nos permitieron reconstruir el contexto histórico, político y social de la provincia y el municipio en el cual se gestionó la construcción del edificio de la escuela. Al mismo tiempo, se indagó en la concepción del proyecto arquitectónico, las referencias y los condicionantes que motivaron a sus autores en su definición, el contexto disciplinar y las características y aportes particulares de la obra.

También se hizo un relevamiento métrico y gráfico de la edificación actual, con el fin de extraer información vinculada a características formales y constructivas, así como para identificar sus transformaciones respecto al estado original. El redibujado de planos se identifica como una técnica valiosa en el estudio de la arquitectura. En este caso, permitió reconocer las características principales de la obra original y definir su transformación en el tiempo. También se cuantificaron los diferentes espacios en cuanto a superficie y altura de la edificación, para contrastar con el entorno histórico y actual, e identificar materiales constructivos, visuales, patologías edilicias y los cambios de uso de los diferentes espacios.

Además de lo anterior, se hicieron entrevistas semiestructuradas (Valles, 2000), a fin de recabar información respecto de las percepciones de los pobladores locales y usuarios sobre el edificio y su entorno. Mediante este método se obtuvo información que no se puede observar directamente, pero que era necesaria para comprender los procesos y las valoraciones en torno al bien escolar. La selección de los informantes se hizo con base en un muestreo intencional considerando a los actores relevantes de la institución educativa: directivos y celadores. Luego, mediante el método bola de nieve (Alloati, 2014), se accedió a algunos vecinos del lugar ${ }^{2}$.

\footnotetext{
2 Interesa aclarar que las entrevistas se realizaron en época de vacaciones, y coincidieron con la noticia sobre la posible demolición del edificio, razón por la cual fue difícil acceder a actores dentro de la institución para entrevistar, y por ello se trabajó con los ya mencionados que trabajan durante este periodo de receso vacacional de clases.
} 


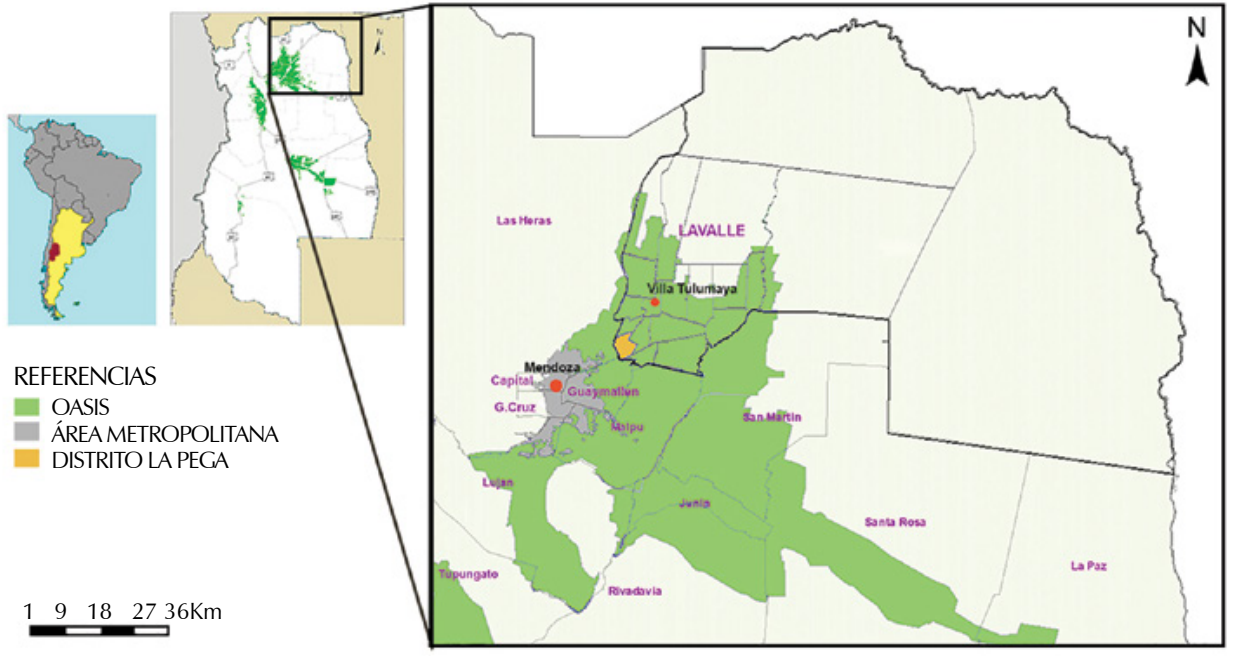

Para acometer las entrevistas se construyeron previamente categorías de análisis en relación con el marco teórico, que se utilizaron como guía. Así, mediante la observación y las entrevistas se registraron datos respecto de la importancia del edificio en el pueblo, las actividades que concentraba y las que actualmente se realizan por fuera del ámbito educativo, el lugar de nacimiento de los entrevistados — para saber si son exalumnos de institución-, sus percepciones respecto al edificio y su estado de conservación, etc.

\section{Resultados}

\section{Caracterización de la obra original en su contexto natural y cultural}

El departamento de Lavalle se encuentra en el noreste de la provincia de Mendoza. El centro departamental, Villa Tulumaya, se emplaza a 34 $\mathrm{km}$ de la capital provincial. Su posición periférica ha incidido en el desarrollo social y económico del departamento y ha determinado el histórico perfil rural que lo ha caracterizado. La zona presenta un clima árido, con precipitaciones que no superan los $200 \mathrm{~mm}$ anuales y de una gran amplitud térmica diaria y anual. El departamento de Lavalle posee el $3 \%$ de su superficie con acceso a riego ${ }^{3}$ - que pertenecen al oasis norte de la provincia- y el $97 \%$ restante de su superficie corresponde a las tierras secas no irrigadas (Grosso y Raffani, 2013). Ello ha condicionado su demografía y las actividades productivas que se registran históricamente en este sitio.

La escuela Arias se emplaza en el distrito de La Pega, al suroeste de Lavalle y dentro del territorio irrigado, tal como se indica en la figura 1. Este distrito es uno de los portales de acceso al departamento, donde la población se concentra en torno a la

3 La provincia de Mendoza se emplaza en la diagonal árida sudamericana de tierras secas, donde se configuran dos subregiones en torno a la apropiación y el uso del agua. Por un lado, las tierras secas irrigadas - oasis-, territorios con mayor acceso al agua superficial y, por ende, al riego, y con posibilidad de cultivo, y donde se asienta la mayor densidad poblacional. Por otro, las tierras secas no irrigadas, con baja densidad poblacional, escasa presencia de agua superficial y actividades ganaderas de subsistencia (Gobierno de Mendoza, 2016) ruta provincial N. ${ }^{\circ} 24$, que conecta el área metropolitana de Mendoza con la villa cabecera de Lavalle. De acuerdo con relatos históricos, este paraje se caracterizaba por presentar suelos con baja absorción del agua, lo que significaba que cuando llovía el camino se volvía intransitable, razón por la cual las carretas quedaban pegadas en el barro y había que esperar su drenaje para poder continuar. De ahí derivan su nombre y su condición de parada en el camino (Maza, 1990). La Pega ha sido tradicionalmente una zona rural con viviendas dispersas, donde la población trabajaba en los campos cultivados o en establecimientos industriales de la zona; principalmente, en bodegas.

De acuerdo con los registros escritos existentes en el establecimiento ${ }^{4}$, la escuela Francisco Arias fue fundada en 1919, bajo la dirección de Carlos Garet. En sus orígenes funcionó en una propiedad del señor Vitolicio Barbini y estaba emplazada en el distrito de El Chilcal, al norte de su ubicación actual. Se trataba de una vivienda de tres habitaciones contiguas. Dos de ellas servían de aulas de primer y segundo grado, y en la tercera vivía el director. Contaba también con una amplia galería y un gran patio con árboles. Según la entrevista realizada a los actuales directores de la escuela, dicha vivienda estaba construida con tierra cruda: los muros eran de adobe y quincha. La cubierta estaba formada por correas de madera y una malla de caña, sobre la cual, a su vez, se disponía una torta de barro con mínima pendiente.

Según registros escritos en el historial de la escuela, en 1929 las actividades escolares se trasladaron al distrito de La Pega, a una vivienda que era propiedad del señor Carlos Laudecina, también materializada con tierra cruda; no obstante, existía el anhelo de los vecinos de la zona de construir un edificio propio y por mediación de la directora de ese momento, la señora Lucila Guevara, se consiguió para este fin un terreno próximo, de una hectárea de superficie, donado por el señor Antonio Clement, en 1932. La construcción del edificio escolar fue llevada a cabo por el gobierno provincial. Su inauguración tuvo lugar en 1934 y supuso un cambio significativo para la comunidad local y la actividad educativa en la zona.

Respecto a datos obtenidos en registros de la prensa escrita, en 1939, La Quincena Social (LQS) — una revista de actualidad de la zona centro-oeste de Argentina - hacía referencia a las características económicas del departamento de Lavalle.

4 Entre los documentos de valor histórico que se conservan en el archivo particular de la escuela Francisco Arias cabe destacar el Historial de la escuela, una fuente de especial relevancia para la investigación, y que se menciona en varias ocasiones en la reconstrucción de la historia y el contexto de la escuela. Consiste en un registro de la institución, iniciado desde su inauguración y el comienzo de su actividad educativa, en 1919, y en el cual la dirección correspondiente anota información sobre los acontecimientos más relevantes que ocurren durante el año en la escuela y, también, en su comunidad. Además, contiene abundante material fotográfico. Supone una colección de cuadernos con registros anuales que ha ido creciendo con el tiempo y con tantos autores como directores ha tenido la institución. 
Dicho texto recalcaba las condiciones favorables del departamento, que vaticinaban un porvenir destacado en la provincia, asociado a su creciente actividad agropecuaria, frutícola, melífera y vitivinícola; pero, al mismo tiempo, señalaba la demanda de sus habitantes de una mayor atención por parte de los poderes públicos, refiriéndose a su carencia de infraestructura (hídrica, sanitaria y de vías comunicacionales terrestres) (LQS, 1939). En sintonía con ello, Hirschegger (2010) explica que el departamento de Lavalle presentaba un relativo atraso socioeconómico aún en la década de 1940, cuando su población representaba el $2 \%$ del total provincial (Presidencia de la Nación, 1947), sin presencia de un núcleo urbano fuerte y con predominio de población dispersa.

En materia educativa y según el Censo Escolar de 1943, Lavalle presentaba el $26,1 \%$ de analfabetos y un porcentaje de deserción escolar del $92 \%$, cifras muy superiores a las de la capital provincial, con el 9,6\% de analfabetismo y el $73 \%$ de deserción (Hirschegger, 2010). Estos valores respondían a factores internos y externos del sistema educativo provincial. Entre los internos destaca la falta de edificios escolares y de maestros, así como las malas condiciones de los edificios existentes y la baja densidad de la población, sumadas a su dispersión. Los factores externos eran representados por el trabajo infantil, la pobreza, el mal estado de los caminos y las grandes distancias que se debían recorrer para llegar a los establecimientos educativos (Hirschegger, 2010).

En sintonía con los factores expuestos, el historial de la escuela Arias se refiere, desde su origen, al problema de la falta de asistencia de los alumnos, de especial incidencia durante los primeros meses del curso, que coinciden con la época de mayor actividad vitivinícola. Se citan entre las dificultades para la asistencia el mal estado del camino, las enfermedades epidémicas y "las mil peripecias con las que se tropieza en la vida de campaña". Para el primer curso de la escuela, la inscripción fue de 64 alumnos, y la asistencia media, de 33. En las siguientes 2 décadas el número de inscriptos fue muy variable: fluctuó entre los 32 y los 87 alumnos y no mostró una tendencia determinada. El año del traslado de la escuela desde el distrito de El Chilcal al distrito de La Pega, en 1929, coincide con el de mayor número de alumnos inscritos: un total de 87 , aunque la asistencia media fue de 34, por lo que no tuvo un aumento asociado. En 1934, año en el que se inauguró el nuevo edificio, la inscripción fue de 58 alumnos. Así mismo, en el historial se hace referencia a las características del vecindario: de bajos recursos, de un trato cordial con la maestra y un ambiente familiar.

Respecto a la infraestructura edilicia de Lavalle existente en los años 30, LQS publicó un artículo al respecto que incluía fotografías de los principales hitos del departamento y sus construcciones más modernas, entre las que destacaban sus escuelas que suponían la mitad de las imá- genes (LQS, 1939). Entre los edificios mencionados estaban la escuela Juan Lavalle, ubicada en la villa cabecera y construida a finales de 1920, y las escuelas rurales Francisco Arias de la Pega y Presidente Derqui del distrito Costa de Araujo, ambas inauguradas en 1934. La publicación mencionada pone de manifiesto la importancia atribuida a los edificios educativos en el departamento.

LQS destacaba en 1935 la labor del gobierno provincial respecto a otras provincias del país en materia de educación; particularmente, en la construcción de escuelas:

$$
\begin{aligned}
& \text { Se puede afirmar que, en el orden edificativo y } \\
& \text { cultural, se ha producido una revolución en sis- } \\
& \text { temas y costumbres retardatarias. Las escuelas } \\
& \text { rurales, ofrecían un espectáculo tristísimo. Ni } \\
& \text { aire, ni higiene, ni amplitud, la salud peligraba. } \\
& \text { Recién ahora se ha iniciado un movimiento } \\
& \text { digno de estos tiempos de renovación en el } \\
& \text { que el escolar se le contempla y se le tutela } \\
& \text { dignificando alumnos y maestros en la comodi- } \\
& \text { dad de las aulas, ya que antes, en vez de alzar } \\
& \text { el espíritu, se sentía deprimido en las rudimen- } \\
& \text { tarias pocilgas de campaña. (LQS, 1935, s. d.) }
\end{aligned}
$$

Así mismo, el texto hace alusión a la modernidad de las nuevas instalaciones educativas: "Se trata de edificios antisísmicos, con todas las condiciones exigidas por la ciencia pedagógica moderna y por la arquitectura escolar" (LQS, 1935, s. d.).

Ciertamente, los gobiernos provinciales llevaron a cabo en el periodo 1932-1943 un importante plan de construcción de infraestructura pública que contempló la construcción de escuelas. Los proyectos fueron desarrollados por la Dirección Provincial de Arquitectura, a cargo de Manuel Civit (1932-1938) y Arturo Civit (1939-1943), quienes acometieron esta labor como parte de la construcción de obra pública dedicada a la función social (Durá-Gúrpide, 2018). El carácter racionalista de la obra de Manuel y Arturo Civit estaría asociado al viaje de egresados que estos últimos realizaron en 1928 a Europa, donde permanecieron un año, y a lo largo del cual entraron en contacto con la arquitectura moderna europea (Raffa, 2008). Así, los nuevos centros escolares proyectados por su oficina se alinearon con la vanguardia internacional en materia de arquitectura escolar, donde se destacó el uso de bloques de aulas orientados correctamente para el aprovechamiento de la luz solar, grandes ventanales y amplias superficies de recreo. Conocer a los autores de la obra y su historia fue un dato fundamental para comprender el porqué del uso de la arquitectura racionalista en zonas rurales y el mensaje de progreso que se pretendía dar con dichas construcciones.

La escuela Francisco Arias formó parte de un plan de construcción de trece escuelas: cinco urbanas y ocho rurales. En las zonas urbanas se elaboraron proyectos particulares para cada caso, mientras que en las zonas rurales se optó por el empleo de proyectos tipo para optimizar su ejecución. La construcción de esas escuelas trataría no solo de contribuir a paliar las deficiencias en 
( Figura 2. Fotografía del edificio en la época de su inauguración y dibujo de la planta de la escuela.

Fuente: fotografía, LQS (1939), y elaboración propia, a partir del plano original. CC BY
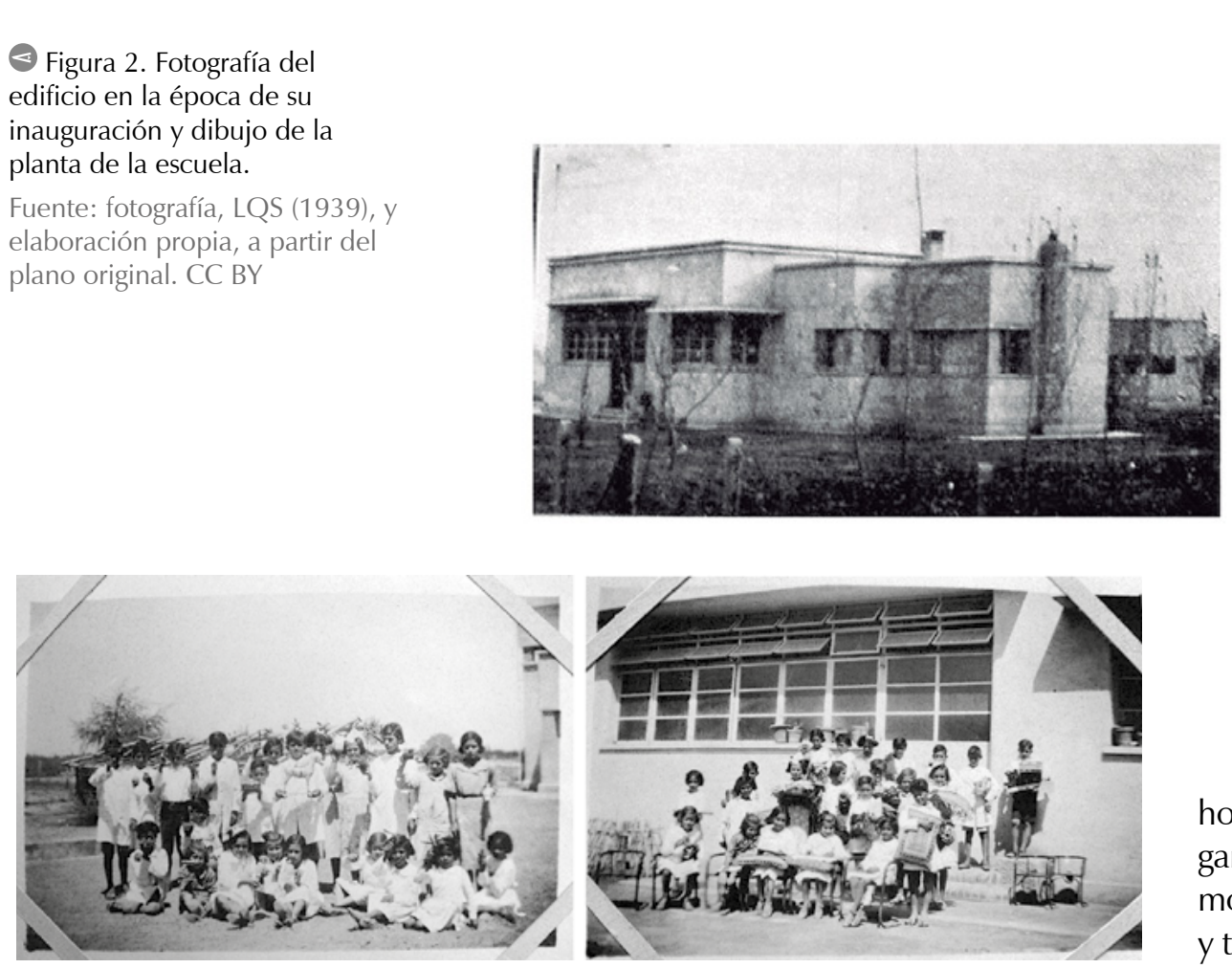

educación de las zonas más carenciadas y que presentaban un mayor número de analfabetos y deserción escolar, sino también, de extender la

(4) Figura 3. Fotografías de la escuela de la década de 1940.

Fuente: Fotografías Historial de la escuela Francisco Arias. CC BY-ND. modernidad al ámbito rural. Dentro de ese plan, en el Departamento de Lavalle, en los distritos de La Pega, El Vergel y Costa de Araujo se construyeron tres escuelas rurales que respondían al mismo proyecto (LQS, 1935).

Este prototipo se denominaba "de tercera categoría" y se caracterizaba por presentar una sola aula para las actividades educativas. Este prototipo fue el más empleado en su época, pues suponía la unidad básica escolar de la que derivaban los proyectos tipo de "segunda categoría" (3 aulas) y "primera categoría" (5 aulas), a los que se adhería un mayor número de aulas conservando las mismas características generales. Estas escuelas de tercera categoría tenían un aula con capacidad para 80 alumnos y vivienda anexa para el director. El aula tenía un espacio principal de grandes dimensiones $\left(55 \mathrm{~m}^{2}\right)$ y otros espacios complementarios asociados: un aula auxiliar contigua de menores dimensiones $\left(20 \mathrm{~m}^{2}\right)$ con depósito $\left(6 \mathrm{~m}^{2}\right)$ y 2 espacios laterales pensados como guardarropas (6 $\mathrm{m}^{2}$ cada uno). La fragmentación del aula planteada respondía a las necesidades de la pedagogía activa, y estaba siendo promovida desde los principales foros de debate sobre arquitectura escolar. La vivienda para el maestro constaba de estar-comedor, cocina, dormitorio y baño (con un total de $43 \mathrm{~m}^{2}$ ). Este prototipo contemplaba también un bloque independiente que albergaba el sector de sanitarios de los alumnos y el tanque de agua, separación que respondía a razones higiénicas. El aula principal contaba con 2 accesos, el principal de los cuales se ubica hacia el este, por donde los alumnos ingresaban atravesando el espacio de recreo, y un acceso secundario ubicado en la esquina suroeste del edificio que utilizaba el maestro, como se muestra en la figura 2.

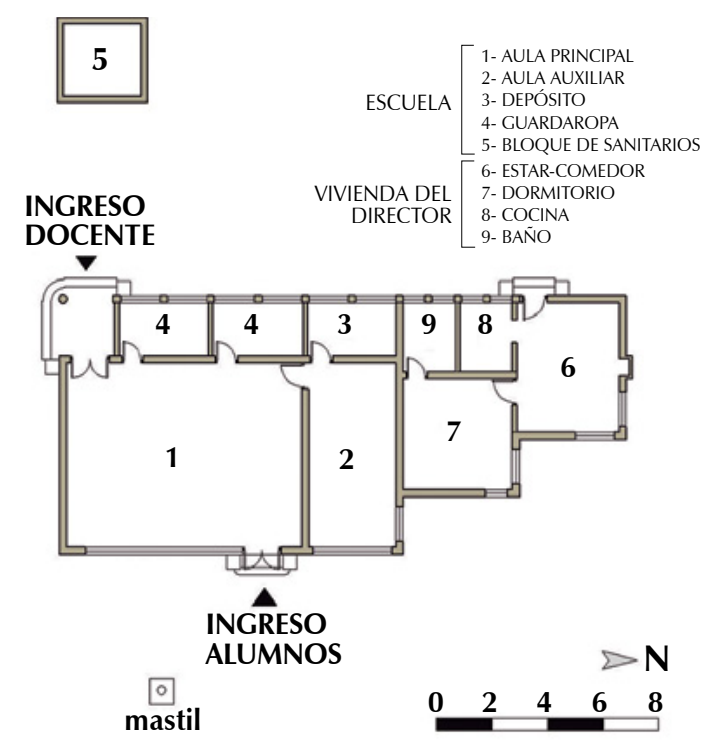

La escuela Arias se construyó con estructura de hormigón armado y muros de ladrillo, con el fin de garantizar su perdurabilidad y su resistencia al sismo. En la cubierta se recurrió a tirantes de pinotea y techos de caña, barro y chapa acanalada de zinc. La cubierta (con una pendiente del 10\%) quedaba oculta tras el remate de los muros por el exterior, para alcanzar una resultante de volúmenes puros, que ocultaba los materiales del techo y su inclinación, como también se aprecia en la figura 2.

También se dispuso de importantes superficies vidriadas, observables en la figura 3, conformadas por la adhesión de módulos de ventanas de menor tamaño — unas fijas, y otras, abatibles-y protegidas de la radiación solar por aleros de hormigón en las aulas, y por persianas metálicas, en la vivienda del director. Se procuró garantizar una adecuada iluminación y ventilación natural según los estándares higienistas de la época y considerando la falta de electricidad; esta última, según lo consignado en los documentos del historial de la escuela, no se instaló hasta 1960. Por el interior se dispusieron cielorrasos de yeso suspendidos a diferentes alturas, según la jerarquía y la escala de cada espacio, y todo el edificio contaba con pisos de baldosa calcárea. En suma, la construcción de la escuela era de una gran calidad para su época y su contexto rural, según se deja ver en la figura 3.

Daniela Cattaneo ha llevado a cabo investigaciones sobre la arquitectura escolar argentina de la década de 1930 en distintas provincias y ha destacado la relevancia de las escuelas rurales mendocinas dentro del marco nacional:

\footnotetext{
Estos prototipos de escuelas rurales manifiestan un salto cualitativo respecto a las iniciativas contemporáneas del resto del país. Se observa una voluntad inclusiva, donde el empleo de materiales y técnicas constructivas locales no los priva de poseer un diseño y una imagen acordes a la normalización a la que responden. (2015, p. 106)
}

Cabe resaltar que Mendoza ha contado con experiencias destacadas en materia de educación dentro del contexto nacional. En efecto, fue la primera provincia en implementar la educación pública gratuita, en 1858, y en sancionar el primer escalafón del magisterio, en 1918. Entre las experiencias pedagógicas de avanzada en la región 
puede mencionarse también la introducción de las ideas de la Escuela Nueva y el sistema Montessori, al final de la década de 1920 (Fontana, 2001; Luquez-Sánchez, 2003). Además, en diversos trabajos se ha destacado el valor de su edilicia escolar como reflejo de los cambios en la disciplina de la arquitectura, de las prácticas pedagógicas y de las condiciones socioculturales (Cirvini, 1994; Cattaneo, 2015; Durá-Gurpide, 2017 y 2018).

Otro de los aspectos que cabe exponer sobre la escuela Arias es su relación con el territorio. Las fotografías muestran el paisaje en el que se insertaba el edificio, de marcado carácter rural y sin construcciones aledañas, y donde resalta como hito en el territorio y se contrapone al paisaje agrario. La arquitectura empleada, con volúmenes puros de carácter abstracto, contrastaba con las edificaciones tradicionales de la zona; sobre todo, dada la gran altura del edificio escolar $(5,25$ $m$ de altura), el uso de amplias superficies acristaladas, los materiales industrializados y el color blanco de sus muros. Por el contrario, las construcciones de la zona - principalmente, viviendasconsistían en pequeños volúmenes de adobe, con una gran galería orientada preferentemente hacia el norte y aberturas de pequeñas dimensiones, para disminuir el intercambio de temperaturas con el exterior (Esteves, 2014). Así, el nuevo edificio de la escuela se reafirmaba como referencia en su entorno y como símbolo de progreso, no solo a través de la educación que ofrecía, sino también, mediante su resolución formal.

Su ubicación en el terreno atendió, principalmente, a su orientación geográfica: los grandes ventanales se orientaron al este para conseguir la mayor iluminación posible en horario escolar. Además, se situó en paralelo a la vía próxima, buscando enfatizar su carácter representativo para la comunidad de La Pega y facilitando la accesibilidad al establecimiento por parte de los alumnos.

\section{Las transformaciones de la escuela}

El edificio y el predio donde se emplaza la escuela Francisco Arias han experimentado distintas transformaciones, en consonancia con el dinamismo de su entorno. Los cambios demográficos, socioculturales y educativos han llevado aparejadas nuevas necesidades, que han implicado la adaptación de la infraestructura escolar. A continuación, se expone una secuencia temporal donde se ana- lizan los cambios más relevantes, según datos consignados en documentos de la escuela que fueron contrastados con las entrevistas realizadas.

Desde su inauguración, en 1934, hasta mediados de la década de 1980, el edificio no sufrió modificaciones; es decir, durante casi 50 años mantuvo su función sin cambios en el proyecto original. Luego, a principios de la década de 1980, se registra la construcción de un bloque con un aula hacia el norte del predio, emplazado de forma independiente y sin conexión directa. En esa nueva aula se concentrarían las actividades del jardín de infantes, para separarlos de los alumnos de mayor edad. A su vez, a finales de la misma década se realiza una ampliación, que consistió en la construcción de un nuevo cuerpo de dimensiones generales similares al primero, pero conformado por tres aulas y dos baños, lo que aumentaba significativamente la capacidad del centro educativo.

El nuevo volumen se dispuso de forma independiente hacia el sector sur del predio, en posición perpendicular al edificio original de la escuela, según se esquematiza en la figura 4 . El nuevo bloque de aulas construido no presentaba la misma resolución formal que el original, pues su altura, por ejemplo, era inferior, y su cubierta era inclinada con gran pendiente (aproximadamente, del $25 \%$ ), lo cual también se muestra en la figura 4. Este bloque disponía de una galería orientada al norte que, aparte de servir como protección solar, incorporaba un espacio de juego cubierto al conjunto. Además, el bloque inicial de sanitarios se refaccionó como cocina, aprovechando las instalaciones sanitarias existentes, lo que permitió mejorar el servicio de la escuela.

La construcción de este nuevo bloque de aulas significó un cambio relevante en el uso del conjunto y en su relación con el entorno, pues la disposición de los bloques contribuyó a la definición de un nuevo patio de la escuela: con una mayor definición de sus límites, donde empezaron a desarrollarse diversas actividades (actos, festejos y recreos). Incluso, la nueva configuración restó protagonismo al frente del edificio, que había supuesto la imagen representativa de la escuela hasta el momento, a favor del patio. También incidió en tal situación el traslado del mástil de la bandera desde el frente hacia el nuevo patio.

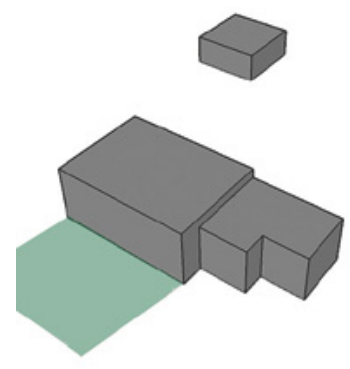

PROYECTO ORIGINAL PATIO

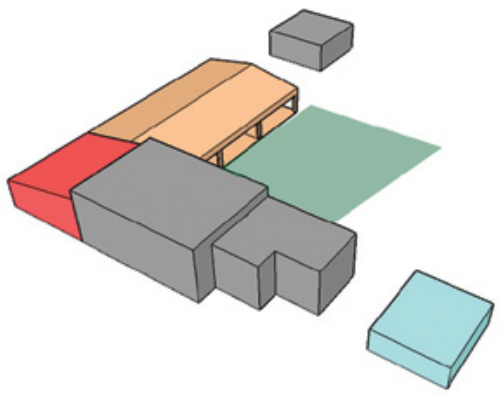

PRINCIPIOS DÉCADA 1980

FINAL DE DÉCADA 1980

PRINCIPIO DÉCADA 1990

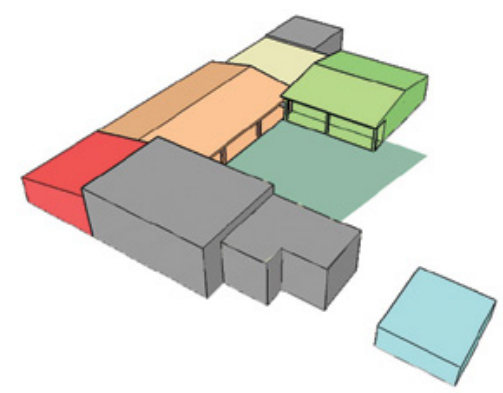

1998

1999
8 Figura 4. Infografía que representa las transformaciones del centro educativo en el tiempo. Fuente: elaboración propia (2018) CC BY 
A principios de la década de 1990 se construyó una nueva aula, que vincularía el edificio original con el nuevo bloque de aulas, para así consolidar la disposición de planta en "L" del conjunto, apreciable en la figura 4.

En 1987 se inició la construcción de otro bloque de dos aulas en un volumen diferenciado. Su edificación fue prolongada, pues se inauguró en 1998; según consta en el historial y en las entrevistas, la demora se debió a dificultades para conseguir financiamiento. Esta nueva construcción se dispuso enfrentada al edificio inicial y a continuación de la primera ampliación, como se ve en la figura 4. De esta manera, el conjunto adquiría una organización en " $U$ " que contribuía a la definición del patio de juegos. La resolución formal de este nuevo bloque se asemejaba a la ampliación realizada en la etapa anterior, con cubierta a dos aguas y una galería orientada hacia el patio central.

Como consta en las fotografías que ilustran los historiales de la escuela, no se registran hasta 1999 nuevos cambios significativos en la estructura y los locales del edificio original. Es decir, hasta ese momento las instalaciones de la escuela se adaptaron a las nuevas necesidades educativas y al incremento en el número de alumnos, mediante la construcción de ampliaciones que adosaban nuevos espacios y no afectaban las características del edificio original.

Fue en 1999 cuando se hizo una serie de reformas al edificio original que afectaron significativamente las características de sus espacios interiores. En el historial de la escuela de ese año consta que "ante los ojos asombrados de los docentes, celadores, alumnos y personas de la comunidad, se comenzó con la remodelación del edificio escolar". Las principales modificaciones realizadas fueron: la división del aula principal para albergar dos locales de igual tamaño —uno para usarse como aula, y el otro, convertido en cocina- y la trasformación del aula auxiliar en una sala de informática con un acceso independiente. También se adaptó la vivienda del director como área administrativa de la institución. Los espacios destinados como guardarropa y depósito se modificaron notablemente, al ser transformados en una galería abierta hacia el patio, desde la cual se accedía a los nuevos espacios, y que proporcionaba continuidad a la galería del conjunto. Estas modificaciones también implicaron cambios sustanciales en el ingreso al predio: se eliminó el acceso original por el lado este y se construyó un corredor de ingreso al centro educativo de 1,50 $\mathrm{m}$ de anchura por el lado sur del aula principal.

Respecto al resto del conjunto, en 2017 se demolieron el último bloque de aulas construido y el bloque de cocina. En 2018 se prevé la demolición del conjunto de las edificaciones existentes de la escuela, para hacer sitio a la construcción de un edificio completamente nuevo.

Según consta en el historial de la escuela, el mantenimiento del edificio estuvo asociado, des- de su inauguración, a la presencia permanente de una comisión cooperadora y el club de madres, integrados por las mismas familias de los niños que asistían a la escuela. Estas se encargaban de recaudar fondos monetarios para las diversas tareas de mantenimiento, como pintura, refacción de aberturas y compra de materiales durante todos los años escolares. Estas dos agrupaciones y las tareas que realizaban figuran en documentos escritos de la escuela hasta la década de 1990, momento en el que las tareas de mantenimiento las asume completamente el Estado provincial, a través de la Dirección General de Escuelas.

De acuerdo con el registro fotográfico, se observa que la edificación original se encuentra en buen estado durante la presencia de la comisión cooperadora y el club de madres. Ciertamente, no se han encontrado en los libros de actas reclamos o descripciones respecto a patologías edilicias, que sí se aprecian a simple vista en la actualidad y ponen en evidencia la falta de mantenimiento de los últimos años. En el relevamiento efectuado a inicios de 2018, se observa el mal estado de los cielorrasos en algunos sectores, debido a filtraciones de agua de lluvia y al desprendimiento de revoques por problemas de humedad.

La situación de falta de mantenimiento preocupó a la comunidad, que elevó diversos reclamos hacia el gobierno provincial y la Dirección General de Escuelas; a pesar de recibir anuncios de mejora por parte de las instituciones responsables, estas no llegaron a concretarse. Por tal motivo, en 2014, padres y madres de alumnos del centro se organizaron y cortaron el paso en la ruta provincial N. ${ }^{\circ} 24$, frente al establecimiento, como reclamo para conseguir las mejoras deseadas en la infraestructura edilicia de la escuela.

Algunos entrevistados se refieren a las labores de mantenimiento de las instituciones de gobierno como intervenciones superficiales que no resolvían los problemas existentes, por lo cual las instalaciones se hallaban en una situación de importante deterioro y era necesaria una cuantiosa inversión monetaria para su reparación. Durante el relevamiento hecho en la actualidad (inicios de 2018) se observaron las problemáticas de patologías constructivas ya mencionadas; no obstante, interesa aclarar que el edificio de la escuela se encontraba en general en buen estado -lo que pone de manifiesto la calidad de la construcción original- y que estaba en condiciones de recuperarse y ponerse en valor.

\section{Las voces de los actores locales: percepciones y valoraciones}

Ya se ha comentado que hay espacios o edificios que se cargan de significados en relación con las diversas prácticas sociales realizadas en su interior. En este sentido, se han identificado dos situaciones respecto a la valoración de la escuela por parte de la comunidad: por un lado, la población originaria de La Pega y, por otro, la población 
ajena a La Pega, pero que vive en el distrito desde hace pocos años, en barrios próximos de reciente construcción.

En las entrevistas realizadas, los directivos de la escuela y los celadores oriundos de La Pega mostraron, en general, emociones positivas respecto al edificio, ya que lo identifican como referente de la zona y como parte de la historia del poblado. A ello se suma que sus padres y sus abuelos habían concurrido al establecimiento, lo que agregaba un plus respecto a las valoraciones asociadas a la historia familiar; no obstante, cabe destacar que en las entrevistas realizadas solo algunos actores reconocían el valor del edificio por sí mismos. Otros, en cambio, lograron hacerse conscientes del valor del inmueble durante las entrevistas, cuando se les preguntó sobre la importancia del bien para ellos y su rol en la historia de la comunidad.

En efecto, durante las visitas al establecimiento, cada vez más entrevistados relataban la importancia del edificio para la comunidad y aportaban datos respecto a anécdotas e historias. En una de las visitas realizadas al establecimiento, los directivos comentaron que frente a su inminente demolición y a partir de las entrevistas realizadas, decidieron colocar como fondo del diploma que se entrega a los alumnos que egresaban ese año una foto del edificio escolar. Indagar en la historia de La Pega y el valor del edificio implicó que los actores locales movilizaran diversos sentimientos hacia el bien como referente y lo plasmaran como elemento que identifica al lugar.

Además de las entrevistas, en los registros escritos y fotográficos del historial de la escuela consta la realización de diversas actividades de diferente índole - familiar, escolar, patrio, etc.- dentro del predio de la escuela. Esto se vincula con el hecho de que la escuela funcionaba como una "gran familia", donde la comunidad entera se reunía para celebrar diversas festividades. En este sentido, la población local también tenía su rol dentro de los actos o los festejos que se realizaban, pues, por ejemplo, consta en los documentos escritos de la escuela que el club de madres se encargaba de conseguir "masas y chocolate" para el cierre de los actos, o que los vecinos conseguían árboles y los plantaban junto a los alumnos. A eso se suma, como ya se mencionó, que las familias resultaron ser el sostén continuo de la escuela durante casi 50 años. Ciertamente, dichas actividades influyeron en la consideración de la escuela como un referente del poblado, lo que generaba su apropiación; no obstante, diversos pobladores locales hicieron referencia al deplorable estado actual del edificio, por su falta de mantenimiento, y la necesidad de contar con un inmueble que responda a las necesidades actuales de la actividad educativa.

También se encontraron valoraciones negativas, vinculadas con algunos pobladores recientemente trasladados al distrito y que no guardan relación con la historia de La Pega. Estos actores aparecen en el territorio cuando el Instituto Provincial de Vivienda edifica dos barrios en los alrededores de la escue- la, en 2000. Los adjudicatarios de esas viviendas provenían de diversos sectores de la provincia, y por ende no presentan la misma valoración que la de los actores que nacieron y crecieron en torno a la escuela y el poblado. Estos nuevos actores se encontraron con un edificio en mal estado, sumado ello a la falta de referencias sobre la importancia del bien en la historia de la comunidad.

En el caso de La Pega, y de acuerdo con las entrevistas realizadas, los edificios históricos de referencia son solo dos: la escuela Francisco Arias y el club social. Por ello, la conservación y la puesta en valor del establecimiento escolar resultan cruciales, en el sentido de reconocer la importancia que representa dentro del marco de la historia de la comunidad y como elemento de referencia y punto de encuentro. En este sentido es donde se coincide con Gutiérrez y Petrina respecto al patrimonio en el contexto latinoamericano para aprovechar las construcciones con posibilidad de vida útil. La conservación del edificio no implica continuar irremediablemente con su uso original, sino que, a partir del reconocimiento de sus valores materiales e intangibles y de su rol en la historia del poblado, este puede cambiar su uso para adaptarse a las necesidades actuales de la escuela o plantear su reutilización por la comunidad, de manera independiente de la escuela. Para el primer caso, y aprovechando las dimensiones del aula original, el edificio podría adaptarse como biblioteca, salón de usos múltiples, sala de informática u otra actividad que requiera espacios amplios. Fuera del ámbito de la escuela, podría utilizarse como centro de integración comunitaria o biblioteca pública, actividades que actualmente carecen de espacio físico en el distrito. En todo caso, su puesta en valor permitiría la resignificación de este espacio como ámbito cultural y símbolo de progreso para su comunidad.

No obstante, respecto a las diversas posibilidades de uso o reutilización, se coincide con Vázquez-Piombo (2016) cuando expone que algunos de los problemas principales del patrimonio construido radican en la falta de flexibilidad y creatividad para vincular nuevos usos dentro y fuera de los edificios patrimoniales. En este sentido y en el interior de la escuela Arias, uno de los entrevistados comentó que para el gobierno, “[...] la idea de que funcione el edificio como un centro comunitario o biblioteca pública -independiente a la organización de la escuela, pero en el mismo predio-, es complicado a nivel institucional y organizativo" (Entrevista a docente. Trabajo de campo, 2018). Es, justamente, esta visión la que afecta a la conservación y el uso de la edificación como referente de toda una comunidad. En efecto, su conservación y su puesta en valor tienen que ver con la historia de La Pega, como uno de los edificios de mayor incidencia en el desarrollo del poblado. En esto radica la importancia de considerar el patrimonio como factor de desarrollo local, al poder aprovechar el edificio para su uso como parte de la escuela o fuera de esta, pero rescatando su importancia dentro del territorio y según su desarrollo histórico. 


\section{Discusiones y reflexiones}

El abordaje del estudio de un bien arquitectónico, la escuela Francisco Arias, desde el enfoque del patrimonio cultural ha permitido enriquecer la lectura del edificio y su significado para la comunidad local, a la vez que considerar a la obra dentro de su contexto natural y cultural.

El caso de estudio deja patente que la población local juega un papel fundamental tanto en el reconocimiento como en la posible activación y la gestión del patrimonio. Ciertamente, a partir de las entrevistas efectuadas se pudo verificar la importancia de la escuela para la comunidad como punto de encuentro y foro de la memoria. Además, el valor de este espacio atiende a distintas generaciones y la presencia de la población en la escuela para la realización de diferentes actividades y celebraciones implica volver a un lugar conocido, propio, a un espacio vivido y cargado de significados.

También inciden en la valoración patrimonial las características propias del edificio respecto a sus valores arquitectónicos. Se trata de una edificación de avanzada donde la arquitectura respondía de forma clara a las necesidades propias de la pedagogía en relación con los debates de la época respecto a las edificaciones escolares y con una concepción arquitectónica propia de la modernidad.

De acuerdo con los resultados plasmados en el trabajo, se reconocen tres aspectos principales que inciden en la demolición de la escuela por encima de su reconocimiento y su protección. Por un lado, la falta de "monumentalidad" del edificio, ya que las escuelas recientemente declaradas como patrimonio por su localización en zonas urbanas presentan mayor visibilidad y mayores dimensiones, a pesar de que estas y la escuela Arias son del mismo periodo temporal y sus proyectos fueron elaborados por los mismos arquitectos bajo los mismos postulados. Además, en el abordaje del edificio en relación con su entorno, queda de manifiesto que la escuela Arias presentó en sus orígenes un carácter monumental frente al marcado paisaje rural donde se encontraba.

Por otro lado, también incide la falta de turismo en La Pega, lo cual podría potenciar el reconocimiento y la conservación del inmueble. En este sentido, el trabajo presenta una mirada sobre las zonas rurales que difiere de aquellos trabajos centrados en la articulación entre turismo y patrimonio, y principalmente, con aquellos que abogan por el turismo como principal motor de desarrollo de las zonas rurales. En este caso, el reconocimiento del patrimonio tiene que ver con el fortalecimiento en el interior de la comunidad, la generación de puntos de encuentro y la puesta en valor de la memoria y la identidad. Si bien la consideración de la escuela como patrimonio no supondría un rédito económico significativo, si lo haría en el plano social.

El tercer factor es la escasa consideración de la población local como actor clave dentro del territorio, pues frente a la inminente demolición del edificio, no se registran consultas a la población local respecto a estas iniciativas, lo cual demuestra que las decisiones respecto al futuro de un bien patrimonial son tomadas por unos pocos actores soslayando las voces de la comunidad. Se ha demostrado que el patrimonio edificado podría actuar como una herramienta válida para la gestión del territorio que sirva, como bien explica UNESCO (2016), para la creación de ciudades más inclusivas, creativas y sostenibles.

\section{Conclusiones}

A lo largo del trabajo se han presentado los valores históricos y artísticos de la escuela Arias, los cuales se enriquecen a partir de considerar su relación con el territorio en el tiempo. A esto se suman las valoraciones que la comunidad local ha plasmado en el edificio a partir de las tareas de mantenimiento que fueron realizadas por más de 50 años por parte de los vecinos y los padres cuyos hijos concurrían al establecimiento. También ha incidido en tal situación el hecho de que la escuela condensaba las actividades familiares y los diversos festejos del poblado, y provocó así la apropiación del edificio por parte de la comunidad.

Por lo anterior, en la articulación entre los valores materiales - históricos y creativos - que presenta el edificio, sumados a los valores simbólicos que le asigna la población local, es como se considera a la escuela Arias patrimonio cultural; sin embargo, el reconocimiento de estos valores y su importancia dentro de La Pega es escaso por parte de algunos pobladores, así como desde las entidades gubernamentales y de la sociedad en general. Estos últimos aspectos explican su falta de mantenimiento en las últimas décadas y su próxima demolición.

A partir de los resultados presentados, se da cuenta del edificio escolar como patrimonio de zonas rurales y su vinculación estrecha con la comunidad local, ya que son los miembros de esta última quienes le asignan valor de uso, se apropian de la obra y la convierten en referente de identidad dentro del marco de su cotidianeidad. Por ello, el reconocimiento del patrimonio arquitectónico en zonas rurales se presenta como una herramienta clave para guiar el desarrollo local exigiendo una gestión gubernamental comprometida con los valores de las comunidades, lo que en muchos casos implica la consideración de aspectos sociales por encima de los económicos.

Quedan pendientes de respuesta las razones que motivan a los actores gubernamentales a favorecer la demolición del edificio antes que a su puesta en valor y su conservación y la forma como se toman las decisiones sobre estos bienes, que deberían ser reconocidos como patrimonio cultural. Se ha comenzado un camino de identificación del patrimonio escolar asociado a poblados rurales. Tal como se expresaba en la introducción, las escuelas construidas en Lavalle durante la década de 1930 son diversas, por lo cual este es el puntapié inicial que nos llevará a continuar indagando en la importancia de este patrimonio para las comunidades de las zonas rurales agrícolas del noreste de Mendoza. 


\section{Referencias}

Alloatti, M. (2014). Una discusión sobre la técnica de bola de nieve a partir de la experiencia de investigación en migraciones internacionales. IV Encuentro Latinoamericano de Metodología de las Ciencias Sociales, 27 al 29 de agosto de 2014, Heredia, Costa Rica. La investigación social ante desafíos transnacionales: procesos globales, problemáticas emergentes y perspectivas de integración regional. Memoria Académica.

Benedetti, A. (2011). Territorio: concepto integrador de la geografía contemporánea. Souto, Patricia (coord.), Territorio, lugar, paisaje. Prácticas y conceptos básicos en geografía (pp. 11-82). Editorial de la Facultad de Filosofía y Letras Universidad de Buenos Aires.

Berón, N., Padilla, C., y Rapali, N. (2013). Nuevo marco normativo de Ordenamiento Territorial en Mendoza: Su aplicación en el Área Metropolitana. Bitácora Urbano Territorial, 22(1). https://revistas.unal.edu.co/index.php/ bitacora/article/view/97-107

Casado Galván, I. (2009, noviembre). Breve historia del concepto de patrimonio histórico: del monumento al territorio, Contribuciones a las Ciencias Sociales.

www.eumed.net/rev/cccss/06/icg.htm

Cattaneo, D. A. (2011). Arquitectura y enunciados pedagógicos alternativos. La experiencia argentina en las primeras décadas del siglo XX. Illapa, 8, 97-116. http://hdl.handle.net/2133/2603

Cattaneo, D. A. (2015). La arquitectura escolar moderna como campo de disputa pedagógica. Claves para una relectura de las escuelas primarias de Mendoza en la década de 1930. Registros. Revista de Investigación Histórica, (12), 95-114.

https://revistasfaud.mdp.edu.ar/registros/ article/view/37

Consejo de Europa. (2000). Convenio Europeo del Paisaje. Disposiciones generales. Florencia.

http://www.upv.es/contenidos/CAMUNISO/ info/U0670786.pdf

Cirvini, S.A. (1994). La configuración de la identidad nacional a través de la escuela argentina. Cuadernos Americanos, 8(44), 167-178. https://www.yumpu.com/es/document/ read/15141171/descargar-archivo-pdf-ahter

Cirvini, S. A. (2012). La valoración como base de la patrimonialización. Actas de las Jornadas Nacionales de ICOMOS. Rutas e itinerarios culturales. De la escala regional a los proyectos trasnacionales. Mendoza, UM, 26.

Conti, A. y Cravero-Igarza, S. (2010). Patrimonio, comunidad local y turismo: la necesidad de planificación para el desarrollo sostenible. Notas en turismo y economía, (1), 8-31. http://sedici.unlp.edu.ar/bitstream/ handle/10915/15769/Documento completo. pdf?sequence $=1$ \&isAllowed $=y$

Cremaschi, V. (2015). La vivienda mendocina en el periodo 1930-1943. Discusiones sobre su implementación. Revista de Historia Americana y Argentina, 50(1), 191-224.

http://www.scielo.org.ar/scielo. php?script $=$ sci_arttext\&pid $=$ S2314$154920150001000008 \& \operatorname{lng}=\mathrm{es} \& \operatorname{tlng}=\mathrm{es}$.

Criado-Boado, F. y Barreiro, D. (2013). El patrimonio era otra cosa. Estudios Atacameños, (45), 5-18.

https://dx.doi.org/10.4067/S071810432013000100002

De la Puente Fernández, L. (2010). El patrimonio rural y su protección. XV Coloquio de Geografía Rural: Territorio, paisaje y patrimonio rural. (Cáceres, 28/04/2010). AGE, Universidad de Cáceres, pp. 471-482.

De Mahieu, G., Bozzano, J., Toselli, C. y ten Hoeve, A. (2003). Comunidad local, patrimonio, ocio y desarrollo sustentable. IMAE, 4. http://fleo.usal.edu.ar/archivos/imae/ otros/a_ocio-05.pdf

Departamento General de Irrigación. (s.f.). Mapa oficial de irrigación [mapa]. Servidor de mapas y cartografía dinámica.

http://www.irrigacion.gov.ar/mapserver/ sicar_web_produccion/intro/paginas/

Durá-Gúrpide, I. (2017), El papel de las revistas especializadas en la génesis de una nueva arquitectura escolar en Argentina, 1930-1943. REFA, Centro de Estudios Históricos "Prof. Carlos S. A. Segreti", Córdoba, 7(7), 213-233.

https://refa.org.ar/file.php?tipo=Contenido\&id $=158$

Durá-Gúrpide, I. (2018). Escuelas para todos los niños, los únicos privilegiados. En: Raffa, C. y Hirschegger, I. (dirs.), Proyectos y concreciones. Obras y Políticas Públicas durante el Primer Peronismo en Mendoza (1946-1955) (pp. 137-172). Universidad Nacional de Cuyo http://bdigital.uncu.edu.ar/11476

Esteves, M. (2014). Territorio y arquitectura: La vivienda vernácula del noreste de Mendoza (Argentina). Zonas Áridas, Lima, (15), 244259.

Flores, F. (2004). La arquitectura como territorio. Cuaderno Arteoficio, (3), 7-12.

Fontana, E. (2001). La escuela media mendocina entre 1864 y 1939. En A. Puiggrós (Dir.), Historia de la Educación Argentina IV. La Educación en las Provincias y Territorios Nacionales (1885- 1945) (pp. 239-298). Galerna.

Gobierno de Mendoza. (2016). Plan Director del Río Mendoza.

http://economia.mendoza.gov.ar/ wp-content/uploads/sites/44/2016/08/ PENSADOPlan_directorMza_octubre06.pdf

Gobierno de Mendoza (2017). Comenzó a construirse la nueva escuela Francisco Arias en Lavalle. Mendoza, Argentina. Prensa Gobierno de Mendoza.

http://www.prensa.mendoza.gov.ar/ comenzo-a-construirse-la-nueva-escuelafrancisco-arias-en-lavalle/

Gómez-Álzate, A. (2010). El paisaje como patrimonio cultural, ambiental y productivo: Análisis e intervención para su sostenibilidad. Kepes, 7(6), 91-107.

http://vip.ucaldas.edu.co/kepes/downloads/ Revista6 6.pdf

Grosso, V. y Raffani, M (2013). Territorios de progreso y territorios de escasez. La apropiación y distribución del agua en la cuenca del río Mendoza, Argentina. Huellas (17), 73-91. https://cerac.unlpam.edu.ar/index.php/ huellas/article/view/853

Gutiérrez, R. y Petrina, A. (Dir.) (2011), Patrimonio Arquitectónico Argentino. Memoria del Bicentenario (1810-2010), Tomo I. Secretaría de Cultura de la Presidencia de la Nación.

Hirschegger, I. (2010). La enseñanza primaria en el marco del Estado de Bienestar: los planes de obras y la expansión de los servicios educativos en dos municipios de Mendoza/Argentina (1946-1955). Antíteses, 3(6), 991-1021. http://www.uel.br/revistas//uel/index.php/ antiteses/article/viewFile/4810/7057

La Quincena Social (1 de enero de 1935). Dirección General de Escuelas. La labor de 1934. pp. $375-376$.

La Quincena Social (1939). El departamento de Lavalle. pp. 482-483.

Llull-Peñalba, J. (2005) Evolución del concepto y de la significación social del patrimonio cultural. Arte, Individuo y Sociedad, 17, 177-206

Lourés-Seoane, M. L. (2001). Del concepto de "monumento histórico" al de patrimonio cultural. Revista de Ciencias Sociales, 4(94), 141150.

https://revistacienciassociales.ucr.ac.cr/ images/revistas/RCS94/10.pdf
Luquez-Sánchez, E. (2014). La experiencia de Escuela Nueva en Mendoza, Revista Historia de la Educación Latinoamericana, (5). https://revistas.uptc.edu.co/index.php/ historia educacion_latinamerican/article/ view $/ 27 \overline{7} 1$

Maza, J. I. (1990). Toponimia, tradiciones y leyendas mendocinas. Fundación Banco de Boston.

Ministerio de Justicia y Derechos Humanos. (8 de agosto de 2017). Monumentos Históricos Nacionales. [Decreto 624/2017]. http://servicios.infoleg.gob.ar/infolegInternet/ anexos/275000-279999/277957/norma.htm

Nogue, J. (2007). La construcción social del paisaje. Editorial Biblioteca Nueva.

Pastor, G. C. (2007). Patrimonio y turismo ¿Quién sirve a quién en la construcción del paisaje cultural? Jornadas de paisajes culturales en Argentina, ICOMOS. Rosario, Argentina.

Prats, L. (2005). Concepto y gestión del patrimonio local. Cuadernos de Antropología Social, (21). h ttps://www.researchgate.net/ publication/39343082_Concepto_y_gestion_ del_patrimonio_local

Presidencia de la Nación (1947). IV Censo General de la Nación. Población. Tomo I. Dirección Nacional del Servicio Estadístico de Argentina.

Quintana Andrés, P. (2008). El hábitat y la vivienda rural en Canarias: Las transformaciones históricas de un espacio social. Rincones del Atlántico, (5), 10-79.

Raffa, C. (2008). La vanguardia racionalista en Mendoza: la obra de los arquitectos Manuel y Arturo Civit. Revista de Historia de América, 139, 181-205.

Raffa, C. (2009) Sobre arquitectos y arquitectura moderna en Mendoza, 1930-1960. Área, 15, 39-53.

Raffa, C. y Cirvini, S. A. (2013). Arquitectura Moderna: autores y producción en Mendoza, Argentina (1930-1970). Arquitecturas del Sur, 31(43), 34-47.

UNESCO (2016). Culture Urban Future. Global report on culture for sustainable urban development.

h t t p : / / u nesdoc.unesco.org/ images/0024/002462/246291e.pdf

Utrera-Santander, S. (2016). El paisaje como patrimonio cultural. Desde una visión monumental del patrimonio a una territorial. Revista Cambios y Permanencias, (7), 452-488. https://revistas.uis.edu.co/index.php/ revistacyp/article/view/7057

Valera-Pertegàs, S. (1996). Análisis de los aspectos simbólicos del espacio urbano. Perspectivas desde la psicología ambiental. Psicología Universitas Tarraconensis, 18(1), 63-84.

http://bibliotecadigital.academia.cl/ handle/123456789/593

Valles, M. S. (2000). Técnicas cualitativas de investigación social. Editorial Síntesis.

Vázquez-Piombo, P. (2016) Arquitectura contemporánea en contextos patrimoniales. Una metodología de integración. ITESO. https://rei.iteso.mx/bitstream/ handle/11117/3844/9786079473433. pdf?sequence $=2$

Venturini, E. (2010). La gestión del patrimonio y el desarrollo integral de las comunidades locales. Jornadas patrimonio y desarrollo. La Plata, Argentina. 
Vol.

NrO. 2 REVISTA DE ARQUITECTURA

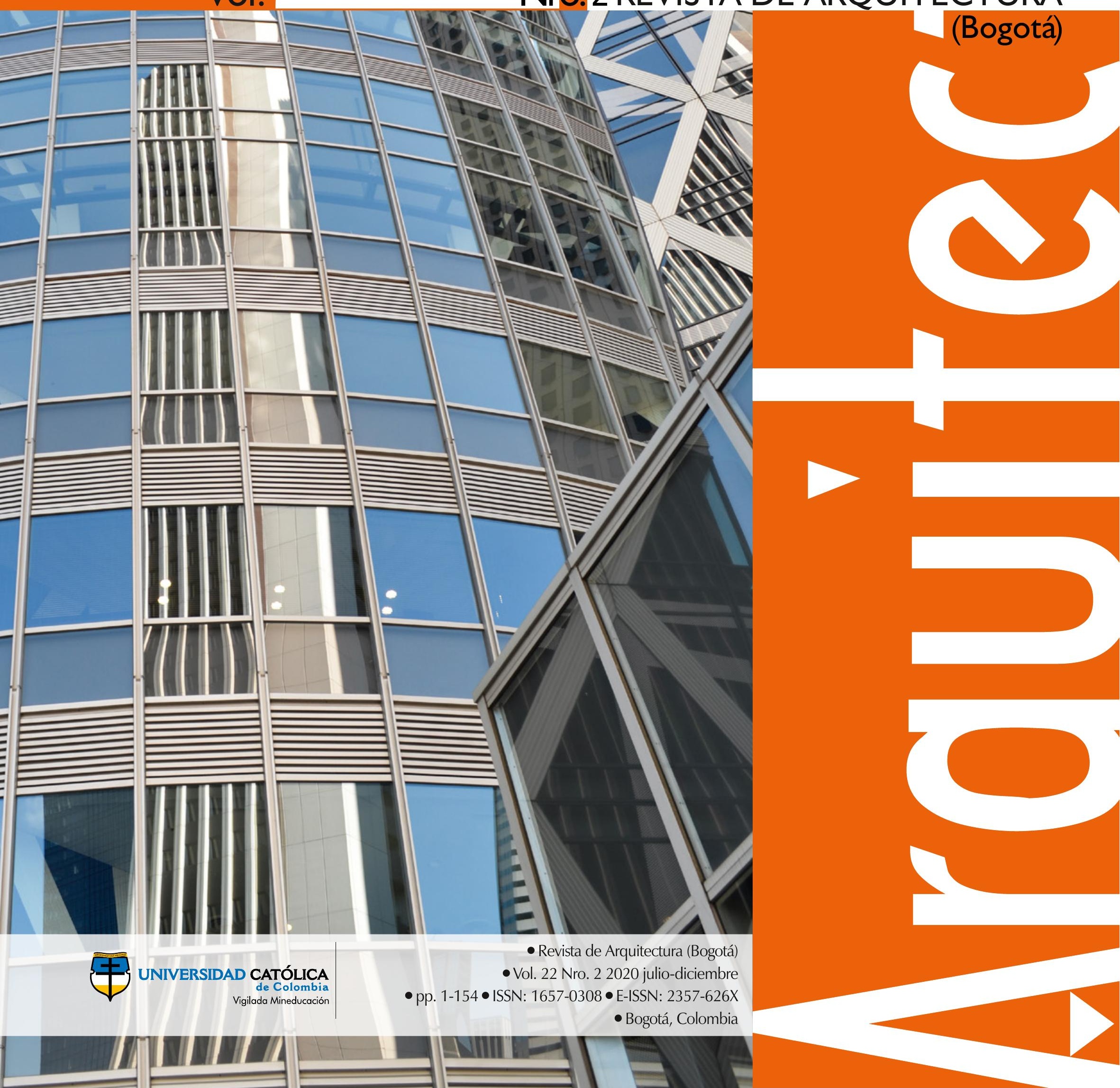


A Portada: Sokkuri (significa reflejo inverso) Mode Gakuen Cocoon Tower, Shinjuku, Tokyo, Japan Fotografía: Arquitecto José Tomás Pachajoa-Herrera (2012, diciembre)

\section{Enfoque y alcance}

La Revista de Arquitectura (Bogotá) ( (ISSN 1657-0308 Impresa y E-ISSN 2357-626X en línea) es una publicación científica seriada de acceso abierto, arbitrada mediante revisión por pares (doble ciego) e indexada, en donde se publican resultados de investigación originales e inéditos.

Está dirigida a la comunidad académica y profesional de las áreas afines a la disciplina. Es editada por la Facultad de Diseño y el Centro de Investigaciones (CIFAR) de la Universidad Católica de Colombia en Bogotá (Colombia).

La principal área científica a la que se adscribe la Revista de Arquitectura (Bogotá) según la OCDE es:

Gran área: 6. Humanidades

Área: 6.D. Arte

Disciplina: 6D07. Arquitectura y Urbanismo

También se publican artículos de las disciplinas como 2A02, Ingeniería arquitectónica; 5G03, Estudios urbanos (planificación y desarrollo); 6D07, Diseño.

Los objetivos de la Revista de Arquitectura (Bogotá) son:

- Promover la divulgación y difusión del conocimiento generado a nivel local, nacional e internacional

- Conformar un espacio para la construcción de comunidades académicas y la discusión en torno a las secciones definidas.

- Fomentar la diversidad institucional y geográfica de los autores que participan en la publicación.

- Potenciar la discusión de experiencias e intercambios científicos entre investigadores y profesionales.

- Contribuir a la visión integral de la arquitectura, por medio de la concurrencia y articulación de las secciones mediante la publicación de artículos de calidad.

- Publicar artículos originales e inéditos que han pasado por revisión de pares, para asegurar que se cumplen las normas éticas, de calidad, validez científica, editorial e investigativa.

- Fomentar la divulgación de las investigaciones y actividades desarrolladas en la Universidad Católica de Colombia
Palabras clave de la Revista de Arquitectura (Bogotá): arquitectura, diseño, educación arquitectónica, proyecto y construcción, urbanismo.

Idiomas de publicación: español, inglés, portugués y francés.

Título abreviado: Rev. Arquit.

Titulo corto: RevArq

\section{Políticas de sección}

La revista se estructura en tres secciones correspondientes a las líneas de investigación activas y aprobadas por la institución, y dos complementarias, que presentan dinámicas propias de la Facultad de Diseño y las publicaciones relacionadas con la disciplina.

Cultura y espacio urbano. En esta sección se publican los artículos que se refieren a fenómenos sociales en relación con el espacio urbano, atendiendo aspectos de la historia, el patrimonio cultural y físico, y la estructura formal de las ciudades y el territorio.

Proyecto arquitectónico y urbano. En esta sección se presentan artículos sobre el concepto de proyecto, entendido como elemento que define y orienta las condiciones proyectuales que devienen en los hechos arquitectónicos o urbanos, y la forma como estos se convierten en un proceso de investigación y nuevo de conocimiento. También se presentan proyectos que sean resultados de investigación, los cuales se validan por medio de la ejecución y transformación en obra construida del proceso investigativo. También se contempla la publicación de investigaciones relacionadas con la pedagogía y didáctica de la arquitectura, el urbanismo y el diseño.

Tecnología, medioambiente y sostenibilidad. En esta sección se presentan artículos acerca de sistemas estructurales, materiales y procesos constructivos, medioambiente y gestión, relacionados con los entornos social-cultural, ecológico y económico.

Desde la Facultad. En esta sección se publican artículos generados en la Facultad de Diseño, relacionados con las actividades de docencia, extensión, formación en investigación o internacionalización, las cuales son reflejo de la dinámica y de las actividades realizadas por docentes, estudiantes y egresados; esta sección no puede superar el $20 \%$ del contenido.

Textos. En esta sección se publican reseñas, traducciones y memorias de eventos relacionados con las publicaciones en Arquitectura y Urbanismo.
A Frecuencia de publicación

Desde 1999 y hasta el 2015, la Revista de Arquitectura (Bogotá) publicó un volumen al año, a partir del 2016 se publicarán dos números por año en periodo anticipado, enero-junio y julio-diciembre, pero también maneja la publicación anticipada en línea de los artículos aceptados (versión Post-print del autor).

La Revista de Arquitectura (Bogotá) se divulga mediante versiones digitales (PDF, HTML, EPUB, XML) e impresascon un tiraje de 700 ejemplares, los tiempos de producción de estas versiones dependerán de los cronogramas establecidos por la editorial.

Los tiempos de recepción-revisión-aceptación pueden tardar entre seis y doce meses dependiendo del flujo editorial de cada sección y del proceso de revisión y edición adelantado.

Con el usuario y contraseña asignados, los autores pueden ingresar a la plataforma de gestión editorial y verificar el estado de revisión, edición o publicación del artículo.
A Canje

La Revista de Arquitectura (Bogotá) está interesada en establecer canje con publicaciones académicas, profesionales o científicas del área de Arquitectura y Urbanismo, como medio de reconocimiento y discusión de la producción científica en el campo de acción de la publicación.

\section{Mecanismo}

Para establecer canje por favor descargar, diligenciar y enviar el formato: RevArq FP20 Canjes

Universidad Católica de Colombia (2020,
julio-diciembre). Revista de
Arquitectura (Bogotá), 22(2),
I-I52. Doi: 10.14718

ISSN: 1657-0308
E-ISSN: 2357-626X
Especificaciones:
Formato: 34 x $24 \mathrm{~cm}$
Papel: Mate II5 g
Tintas: Negro y policromía

Contacto

Dirección postal:

Avenida Caracas No. 46-72.

Universidad Católica de Colombia

Bogotá D.C.(Colombia)

Código postal: 111311

Facultad de Diseño

Centro de Investigaciones (CIFAR).

Sede El Claustro. Bloque "L", 4 piso

Diag. 46A No. $15 b-10$

Editor, Arq. César Eligio-Triana

Teléfonos:

+57 (1) $3277300-3277333$

Ext $3109 \cdot 311205146$

Fax: + 57 (1) 2858895
Correo electrónico:

revistadearquitectura@ucatolica.edu.co cifar@ucatolica.edu.co

Página WEB:

www.ucatolica.edu.co vínculo Revistas científicas

http://publicaciones.ucatolica.edu.co revistas-cientificas http://editorial.ucatolica.edu.co/ojsucatolica/revistas_ucatolica/index.php/RevArq 


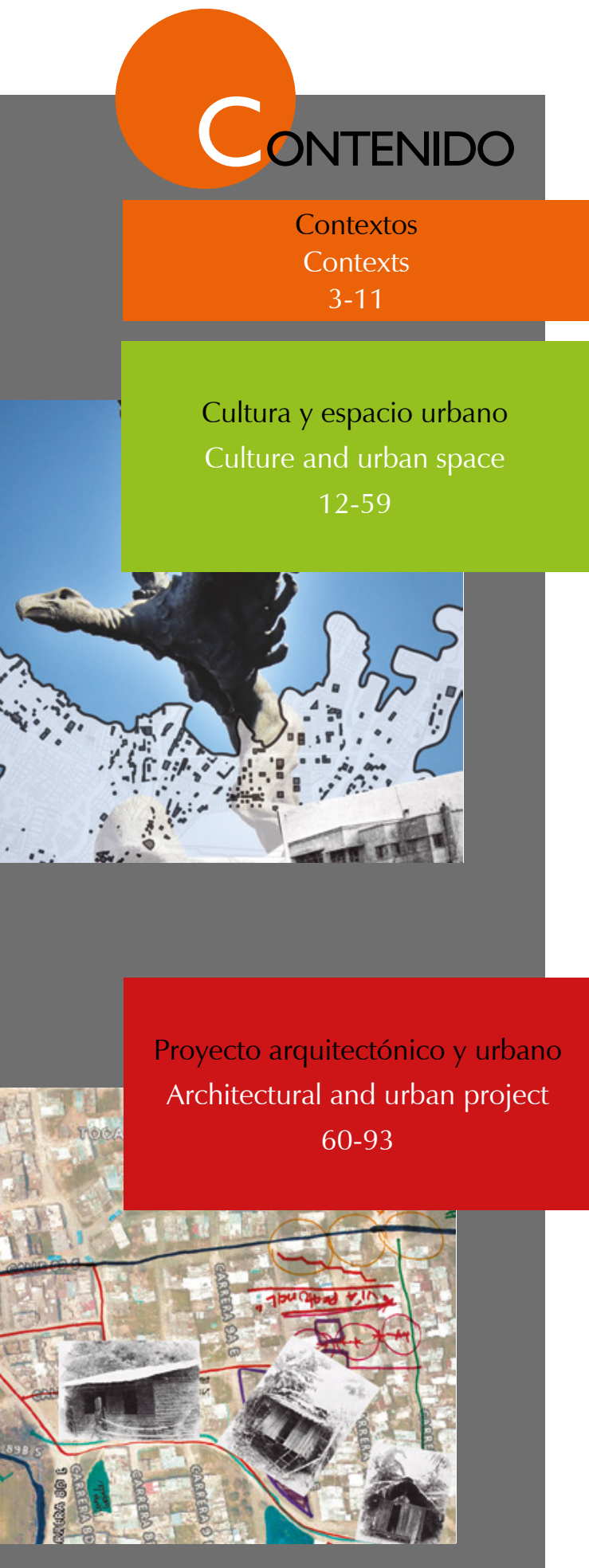

Tecnología, medioambiente y sostenibilidad

Technology, environment and sustainability 94-152

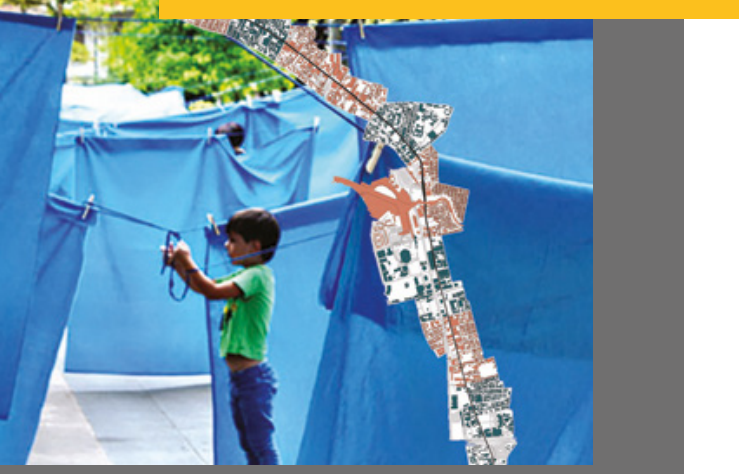

Espacio y tiempo del taller de proyectos arquitectónicos:

la Escuela de Arquitectura de Valencia

Débora Domingo-Calabuig

Laura Lizondo-Sevilla

La comunidad local en la valoración del patrimonio rural.

La escuela Francisco Arias en Lavalle

Isabel Durá-Gúrpide

Matías J. Esteves

ES Hábitat Accesible. Desarrollo de modelos conceptuales urbano-habitacionales.

Alina Delgado-Bohórquez

ES Monumentos y arte urbano: percepciones, actitudes y valores en la ciudad de Manizales.

Rodrigo Santofimio-Ortiz

Sandra Milena Pérez-Agudelo

ES Nueva centralidad en interfase urbano-rural (I-UR)

Caso: sector Umapalca, zona sur de Arequipa Metropolitana

David Jesús Lovon-Caso

Ana de los Ángeles Larota-Sanz

ES Arquitecturas tradicionales y populares: un reto para la historiografía de la arquitectura en Colombia

Guillermo Gutiérrez-Morales

Mito o realidad.

Gustave Eiffel y el templo San Marcos de Arica

Darci Gutiérrez-Pinto

ES La caminabilidad como estrategia proyectual para

las redes peatonales del borde urbano.

Barrio Sierra Morena, Usme.

Marielena Medina-Ruiz

Siudades costeras e indicadores de sostenibilidad:

una aproximación desde el metabolismo urbano de la calle

El caso de la avenida Juan Ponce de León, en San Juan, Puerto Rico

María Helena Luengo-Duque

Fabricación de ladrillos con polvo-residuo de mármol en México. 106

Propiedades físicas y mecánicas del polvo-residuo de mármol

de la provincia de la Comarca Lagunera, en México

C. Ponce-Palafox
Julián Carrillo
A. López-Montelongo

Determinación de emisiones de Gases de Efecto Invernadero (GEI) en una matriz energética sustentable mediante análisis de escenarios.

Estudio de caso en zonas áridas con alto riesgo hídrico

Alba Inés Ramos Sanz

ES La participación infantil en proyectos urbanos.

El juego en espacios públicos para la promoción del aprendizaje

de conceptos ambientales

Carolina Polo-Garzón

Adriana Patricia López-Valencia

Alba Inés Ramos Sanz

ES Gestión territorial y sus implicaciones con el ODS11

Reflexiones desde Colombia y Costa Rica

Tania Giraldo-Ospina

Félix Zumbado-Morales 
Espacio y tiempo del taller de proyectos arquitectónicos:

la Escuela de Arquitectura de Valencia

ن Space and time of the design studio: the Architectu

La comunidad local en la valoración del patrimonio rural. La  escuela Francisco Arias en Lavalle

ن The local community in the appreciation of rural heritage. Francisco Arias ¿ school in Lavalle

Hábitat accesible. Desarrollo de modelos conceptuales

ij Affordable Habitat - The Development of Housing and Neighbourhood

Simulation Models

Monumentos y arte urbano: percepciones, actitudes y valores en la ciudad de Manizales

m ن Manizales $\stackrel{\infty}{+}$ Umapalca, zona sur de Arequipa Metropolitana

New Centrality in Rural Urban Interface. Case: Sector Umapalca, South Zone of Metropolitan Arequip

0

Arquitecturas tradicionales y populares: un reto para la

historiografía de la arquitectura en Colombia

ن Traditional and popular architectures: a challenge for architecture

这

¿ேं

\section{Ciudades costeras e indicadores de sostenibilidad:}

よ

caso de la avenida Juan Ponce de León, en San Juan, Puerto Rico

Coastal cities and sustainability indicators: an approach from the urban

metabolism of the street. The case of Juan Ponce de León avenue, in San Juan, Puerto Rico

Fabricación de ladrillos con polvo-residuo de mármol en México. - Propiedades físicas y mecánicas del polvo-residuo de mármol de 으 la provincia de la Comarca Lagunera, en México

ن Physical and mechanical properties of bricks with dust residue from marble in

México.Physical and mechanical properties of the marble dust-residue from the Comarca Lagunera Province, in Mexico

\section{Julián Carrillo}

Determinación de emisiones de Gases de Efecto Invernadero * (GEI) en una matriz energética sustentable mediante análisis de

- escenarios. Estudio de caso en zonas áridas con alto riesgo hídrico ن Determination of greenhouse gas emissions (GHG) in a sustainable energy matrix $\varangle \quad$ through scenario analysis. Case Study in arid zones with high hydric risk

\section{La participación infantil en proyectos urbanos. El juego en}

ㄴ espacios púb

$\stackrel{2}{\sim}$ ambientales

ن Children's participation in urban projects. Play in public spaces for the

$\varangle$ promotion of the learning of environmental concepts Gestión territorial y sus implicac
desde Colombia y Costa Rica

₹ desde Colombia y Costa Rica

Land Management and its implications with SDG II Reflections from

ن Colombia and Costa Rica

¿ Tania Giraldo-Ospina
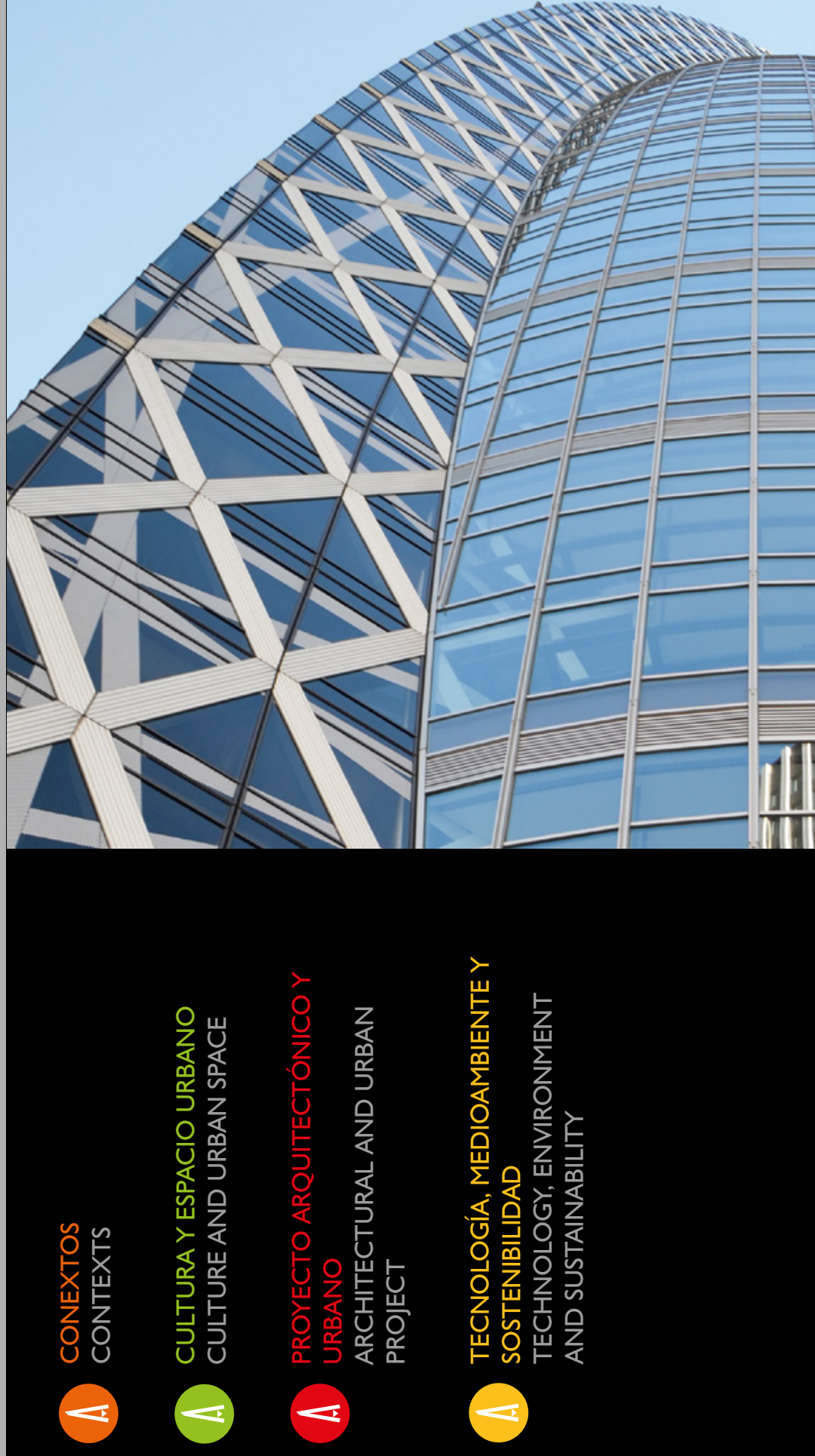

La Revista de Arquitectura es de acceso abierto, arbitrada e indexada y está presente en:

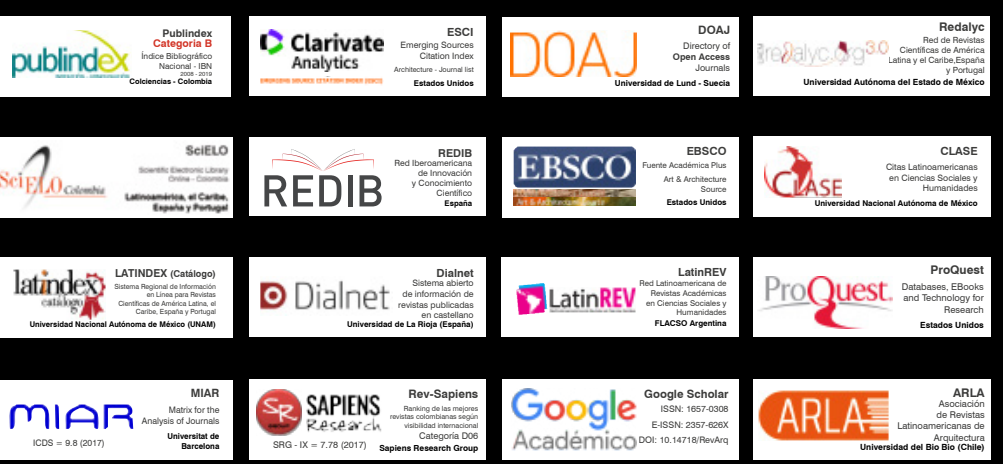

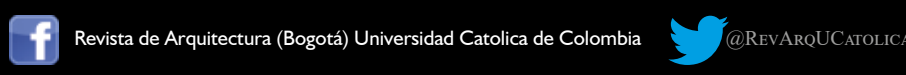

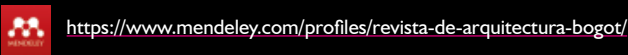

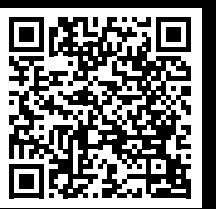

† UNIVERSIDAD CATÓLICA

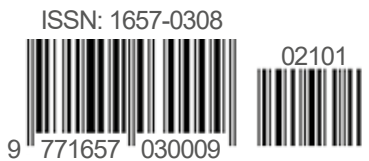

